INTERNATIONAL JOURNAL OF MULTIDisciplinaRy RESEARCH AND ANALYSis

ISSN(print): 2643-9840, ISSN(online): 2643-9875

Volume 05 Issue 02 February 2022

DOI: 10.47191/ijmra/v5-i2-05, Impact Factor: 6.072

Page No.- 279-283

\title{
Adoption of Recommended Beekeeping Practices in Kumaon Hills of Uttarakhand
}

\author{
Dr. Kiran Rana ${ }^{1}$ and ${ }^{2}$ Ishita Mishra \\ ${ }^{1}$ Asst. Prof, Department of Agricultural Communication, GBPUA\&T, Pantnagar, Uttarakhand \\ ${ }^{2}$ M.Sc. Student, Department of Agricultural Communication, GBPUA\&T, Pantnagar, Uttarakhand
}

\begin{abstract}
Beekeeping in Uttarakhand is one of the oldest traditional practices followed both for the commercial purpose as well as the domestic use. It is an important supplementary income generating activity in the state. According to the experts, there is a need to adopt modern beekeeping practices by the traditional beekeepers in the state, especially in the areas like bee management, better extraction, honey storage and quality control. Honey bee farming is now a days becoming more popular due to its market demand in national as well as the international market. The farmers not only obtain economic benefits but beekeeping also helps the farmers increase the agricultural productivity through pollination. Uttarakhand has huge potential for beekeeping due to plenty of flora and suitability of climate but the farmers still depend on the traditional practices resulting in the low yield of honey produce both in terms of quality and quantity. Hence, there is a huge scope of adoption of advanced scientific practices in the state of Uttarakhand that can add to the farmers income in the state. "Mountain farmers in Uttarakhand are facing extreme difficulties in meeting their basic needs because of meager opportunities to engage youth in respectable employment. The paper suggests that the Uttarakhand has tremendous scope for commercial beekeeping and use of bee for pollination of diversity agri-horticultural crops and wild flora. Also, the paper emphasizes on the constraints for beekeeping development and strategies for organic honey production in Mountain hill of Uttarakhand.
\end{abstract}

\section{INTRODUCTION}

Indian agriculture contributes for about 19.9 per cent of GDP and provides livelihood to about 52 per cent of the labour force. More than 50 per cent of the Indian population depends on agriculture and allied activities either directly, indirectly, primarily or secondarily for livelihood. The government of India in its annual budget 2016-2017 set a policy target of doubling the farmer's income by 2022.To double the farmers income there should be an integration of various allied agricultural enterprise together with the crop production system. To double the farmers income, integrated farming system is a good approach which includes allied agriculture practices together with the crop production system. Few allied agricultural enterprises are mentioned as follows Dairy farming, Poultry, Piggery, Dairy, Bee keeping, Sericulture, Mushroom cultivation and Fisheries. An integration of these allied agriculture enterprise minimizes the risk factor associated with agriculture.

One such most important allied agriculture practice in northern hills of India is apiculture, commonly referred as beekeeping. Bee keeping is defined as the scientific method of conservation and rearing of bees for the production of important hive products such as honey, bee-wax, royal jelly, propolis and bee-venom. It is an environmentally friendly and agro-forestry based occupation (Singh and Mishra, 1995). Beekeeping is an important enterprise that involves use of low input and high output sector. Honey is the most important primary product obtained from the beekeeping practices, both from quantitative and economic point of view, and it has been used by the mankind for many years as a source of food, medicine and for cultural ceremonies. Beekeeping has a vast potential for supplementary income generation for the farmers and rural, hilly and tribal populations. It is an excellent source of employment for the rural unemployed. Approximately 2,50,000 farmers in India got employment from beekeeping in the recent past years (Kejriwal, 2012).

India ranks first in number of beehives stocks followed by China in the world and stands at eighth position in terms of World in honey production producing around 95,000 metric tons of honey per annum (NBB, 2016-17). There are several reasons behind this huge gap in availability of beehive stocks and total honey production, one may the partial or no adoption of the recommended beekeeping practice. Out of the total honey production in India, around 61 per cent is contributed by four states viz. West Bengal, Uttar Pradesh, Punjab and Bihar. 


\section{Adoption of Recommended Beekeeping Practices in Kumaon Hills of Uttarakhand}

Uttarakhand is a land of variety of flora and fauna. Beekeeping forms an integral part of the small holder farming system and plays a significant role as a source of additional cash income in subsistence farming. There are around 2,50,000 beekeeping units in India out of which only 8,700 are in Uttarakhand accounting for about 2500 MT of honey production in 2016-17. Uttarakhand is extremely rich in Bee forage plants but the use of this rich resource is not being made properly (Tiwari, 2010). Around 20 per cent of the Beekeepers in Uttarakhand do not use any medicine for the management of pest and diseases showing that the farmers are not much aware of the advance methods of beekeeping (Khan et al., 2007). Uttarakhand has huge potential for beekeeping due to plenty of flora and suitability of climate. Beekeeping is an ancient practice that is managed traditionally in Kumaon hills of Uttarakhand. Due to the traditional production system the productivity per hive is low in Uttarakhand.

\section{Recommended beekeeping practices:}

There is vast potential for beekeeping in the country. However, due to lack of knowledge scientific beekeeping is not being practiced by the beekeepers which is one of the major reasons behind low honey production. In order to obtain high output in terms of the honey produce it is necessary for beekeepers to participate in the trainings and other capacity building programmes to gain scientific knowledge on the subject. Selection of good apiary site, good quality bees and proper management are the main keys for a successful beekeeping enterprise. One should always use recommended methods to control swarming, division of colonies, uniting of colonies, mass queen rearing, stopping laying workers, robbing, desertion, migration, and management of diseases, pest and enemies, etc. The following advisories as formulated by the National Bee Board should be kept in mind for effective and beneficial beekeeping:

\section{A. Selection of good apiary site}

While selecting an apiary site one should make sure that the Apiary ground is clean \& free from dry leaves. This is important to avoid fire during the summer season. The site should be away from power station, brick kilns, highway and train tracks so that the honey produce obtained may be of good quality. Also, the site should be open and should be rich in bee flora. Fresh running water should be easily available near the apiary and the site should have natural or artificial wind breaks. There should not be any source of stagnant , dirty water, chemical industry and sugar mill, etc., nearby the apiary.

\section{B. Selection of good quality bees}

The two most common bee species reared in India are Apis cerena_and Apis mellifera depending upon floral conditions and capability of investments. However, success in both the cases depends on quality of bees, particularly the queen bee. Therefore, certain factors should be kept in mind during the selection of the bee colonies. Only disease-free bee colonies should be bought from existing beekeepers. The Selection and multiplication of the bees should be only from disease resistant, high honey yielding, young, healthy and high egg laying capacity queen. Keep colonies with good prolific queens and capture few bee colonies from their natural abodes in forests which may be used for further breeding/ multiplication to prevent inbreeding.

\section{Management of apiary}

Apiary management is necessary to obtain good quality of output in terms of both quality and quantity that may result in maximum returns to the beekeepers. Following are few apiaries management practices as advised by the National Bee Board:

\section{Placement of colonies in apiary}

The beehive should be as per the specification of BIS/ISI and should be of locally available seasoned light weight wood. Unseasoned and heavy wood should be avoided. Nailing the bottom board with the brood chamber should be avoided and the number of bee colonies in an apiary should be restricted to about 50 to 100 and over stocking of the colonies in apiary should be avoided. The row to row and box to box distance should be about 10 and 3 feet, respectively.

\section{Inspection of colonies}

The beekeeper should make sure to adopt general colony and personal hygiene in the apiary like cleanliness in the beehives including cleaning the bottom board, top cover, etc. frequently. The colonies should be checked periodically for any abnormalities or changes in behaviour of the bees. Inspection of the colonies should be made on clear sunny days preferably at temperatures between 20 and $30^{\circ} \mathrm{C}$. Beekeepers should avoid inspecting colonies in cold, windy and cloudy days. Smoker should be used whenever needed to subdue the bees and the colonies should be handled gently to avoid jerks. The diseased and the healthy colonies should be handled separately.

\section{Provision of fresh water in the apiary}

Water is needed in the apiary for the maintenance of the adequate humidity in the colony to ensure proper incubation of the eggs. When the temperature of the apiary increases, water is used by the bees to evaporate and cool the colonies. Also, for feeding bread by the nurse bee, the mixture of honey and pollen of certain consistency is required for which water is needed 


\section{Adoption of Recommended Beekeeping Practices in Kumaon Hills of Uttarakhand}

\section{Dearth period management}

Dearth period is when nectar flow for honey bee is at minimum, usually when fruits and vegetables have gone from flowering stage to fruiting stage. Provide 50\% sugar syrup to the colonies during dearth periods when honey stores in the colonies is not adequate and nectar is not available in the area. The syrup should be prepared by boiling clean water in the vessel and sugar added with slow stirring for few minutes. Cover the vessel with lid and let it cool. Feed cooled syrup to the honeybee. The Sugar syrup should be kept in such a way that the bees should not drown in it. This should be ensured by using shallow vessels with straw to facilitate easy feeding. The feed should not be prepared in the open and dripping of the feed should be avoided on the ground to prevent robbing by bees and ants. Feed the colonies in the evening preferably after sunset. Feeding should be given to all colonies in the apiary at one time. Do not feed colonies with honey or syrup mixed with honey. Pollen substitute comprising of fat free soyabean flour (3 parts) + Brewer's yeast (1 part) + skimmed milk powder (1 part) + sugar (22 parts) +honey (50 parts) made in the form of patties should be provided when pollen stores in the colonies is not adequate and pollen is not available in the area. Provide fresh water near the colony in shallow vessels Extra frames should be stored in air tight chambers and fumigated with sulphur powder regularly. Old and dark combs should be discarded

\section{Care during honey extraction}

Honey extractor, containers and other bee hive tools or equipment's made of stainless steel or food grade plastic should be used to extract honey. Equipment's and containers should be thoroughly washed with warm water before honey extraction. Honey should be extract from super chambers only. Frames with only with $75 \%$ sealed cells with ripened honey should be used for extraction purpose. Honey should be extracted in a closed room to avoid robbing.

\section{Care during migration}

The bee colonies should be migrated during non-availability of flora to areas with abundant flora. Before migration the area must be surveyed to assess the availability of the flora to locate the colonies. The Beekeepers must ensure honey extraction before migration. The entrance gates of the colonies should be closed in the evening after all worker bees are inside the colony. The colonies should be packed internally and externally before migration to avoid jerking. Colonies in the vehicle should be packed in such a way that the entrance side should face the front side of the vehicle. Migration should start late in the evening and ensure the colonies reach the destination within 10-12 hrs.

\section{SEASONAL MANAGEMENT OF APIARY}

\section{a) Summer management}

During summer season the colonies should be kept in thick shade. The microclimate of the apiary should be regulated by using wet gunny bags over top cover and water should be sprinkled around the colonies in the apiary during noon hours. Proper ventilation should be provided in the colony by widening the entrance gate of the colony, additional gates should also be added to multi chambered colonies, placing thin small stick pieces between two adjacent chambers for the passage of fresh air.

\section{b) Monsoon management}

During monsoon the surroundings of the colony must be kept clean by cutting the unwanted vegetation which may hamper free circulation of the air. Artificial feeding (sugar syrup and/or pollen substitute) must be provided to the bees as per the requirement of the colony .

\section{c) Post monsoon season management}

Colonies must be provided with sufficient space in the colony. The colonies should be strengthened to stimulate drone brood rearing. The ectoparasitic mites, wax moth and predatory wasps should be controlled before the winter sets in.

\section{d) Winter management}

The colonies should be examined and stimulative feeding should be provided to the weak colonies to provide energy and initiate brood rearing. The colonies should be protected from chilly winds by using wind breaks. Unite the weak colonies with stronger ones.

\section{e) Spring management}

During spring provide stimulative sugar or pollen substitute to increase brood rearing. To equalise the colonies extra frames should be raised by providing comb foundation sheets. The old queens should be replaced with new ones through mass queen rearing. Honey should be extracted frequently during this season.

\section{Protecting colonies from pesticides}

The farmers must be persuaded not to use pesticides or use selective pesticides that are less harmful to bees at recommended concentrations. The use of dust formulations must be avoided as they are more harmful to bees than spray formulation. Prior information to the Beekeepers about spraying would help in reducing poisoning of bees. The farmers must avoid spraying of 


\section{Adoption of Recommended Beekeeping Practices in Kumaon Hills of Uttarakhand}

pesticides during flowering of the crop and peak foraging time of the bees. This would help in reduction of mortality in foraging bees. Spraying may be done in the evening after sun set when bees do not forage.

\section{Management of honey bee diseases}

Honey bees could be affected by a variety of diseases and the real cause of abnormality or any disease present in the honey bee broods need to be ascertained before taking up any control measures. It is best to contact researchers, scientists or the beekeeping experts at the nearest centre or university or government department working on honey bees. After the exact diagnosis of the causal agent of the particular disease, the guidelines or the recommendations given by the expert should be followed in true letter and spirit.

\section{Adoption and stages of adoption}

The major goal of the extension community is to get a new or a profitable practice to be adopted by the farming community. Adoption is defined as the decision to make full use of an innovation as the best course of action available. Adoption is essentially a decision-making process. According to Rogers, "adoption process is the mental process through which an individual passes from hearing about an innovation to final adoption". Adoption process occurs at individual level. Wilkening described the adoption of innovation as a process composed of learning, deciding, and acting over a period of time. The adoption of a specific practice is not the result of a single decision to act but a series of actions and thought decisions. There had been always a gap between recommended innovation and their adoption by ultimate users of the technology (Pottappa, K. 2005). The adoption depends on several factors like socio economic, communication and psychological factors which needs to be studied to understand why farmers adopt or do not adopt certain improved practices. The Northern Rural Sociology Subcommittee for the study of diffusion of farm practices 1955 identified five stages of the adoption process, which received worldwide attention.

Awareness: At this stage an individual becomes ware of some new ideas. The existence about the idea is known but the details about the idea is still not know.

Interest: At the interest stage a person wants more information about the idea.

Evaluation: At this stage the individual makes mental application of the new idea to the present and anticipated future situation and decides whether or not to try it. The individual makes an assessment whether the idea is applicable to the situations or not and if applied what will be the results.

Trial: During this stage the individual actually applies the new idea on a small scale in order to determine its utility in own situation. The trial stage is generally characterized by the small-scale experimental use. It may be considered as the practical evaluation of the innovation.

Adoption: This final stage in the process is characterized by large scale, continued use of the idea, and most of all, by satisfaction with the idea. Being satisfied with the trial and considering the pros and cons of the situation, the individual takes the final decision and applies the innovation in a scale appropriate to own situation on a continued basis.

These five stages are not necessarily a rigid pattern which people follow. There can be jumping from one stage to the other. In terms of beekeeping if the farmer has confidence in the extension worker or the scientist recommending an advanced practice, the beekeeper may jump from the evaluation to the adoption stage.

\section{IMPORTANCE OF ADOPTION OF RECOMMENDED BEEKEEPING PRACTICES IN KUMAON HILLS}

In India honey bee pollination services have been reported to increase the yields and quality of many important cultivated crops owing to which beekeeping has emerged as an important component for sustainable development of agriculture and horticulture system. Total area of bee dependent crop for pollination is about 55 million hectare and 200 million colonies are needed to meet this, while at present only 1.8 million colonies are present (NBB, 2017). Hence there is a huge potential for the beekeeping in India. Uttarakhand has huge potential for beekeeping due to plenty of flora and suitability of climate. Beekeeping has a huge potential as a supplementary income generating activity, still it is underutilized in the state. Several constraints which lead to under production of honey in hilly area includes; long dearth period, limited credit supply and subsidy, high cost of supplementary bee feed, lack of post-harvest and management facilities, marketing of honey and unfixed support price for honey. (Bansal et al., 2013). In Uttarakhand about 17 per cent of the apiaries were found to be infected with more than one disease and beekeepers were not aware of improved apiary disease management practices. Around 20 per cent of the beekeepers did not use any medicine for management of the pest and diseases. (Khan et al, 2007). Traditional beekeeping is widely practiced in hilly areas by the rural people who inherit the tradition from their forefathers and are reluctant to adopt and have no information about modern day practices. Improved cultivation practices when adopted for any crop or enterprise has shown to increase the production substantially (Chourasia, 2011). Though India ranks first in bee hive stocks number, still it ranks eight in terms of honey production, which indicates there is lack of adoption of suitable and recommended improved beekeeping practices. 


\section{Adoption of Recommended Beekeeping Practices in Kumaon Hills of Uttarakhand}

\section{CONSTRAINTS FACED BY THE BEEKEEPERS IN ADOPTION OF RECOMMENDED PRACTICES}

There are several constraints that are faced by the beekeepers in adoption of recommended beekeeping practices. According to Shenkute et al. (2012) the low adoption of improved beekeeping technology is because of lack of management and technology development, absence of diversification of bee products (propolis, pollen and other high value of bee products), lack of skilled man power on apiculture to help beekeepers managing honey bees for better production and lack of extension agents. Fikadu et al. (2017) in his study reported that around 44 per cent of the respondent's ranked pest and predators as the first major constraint faced by the beekeeper. About 20.5 per cent of the respondents ranked drought as the second major constraint and 13.4 per cent of the respondent ranked lack of bee keeping equipment's and accessories as the major constraints faced by the beekeepers in adoption of recommended beekeeping practices.

Kumar et al. (2020) mentioned in a study that the economic constraints for non-adoption of improved beekeeping practices include lack of subsidiary, shortage of financial resources for purchasing raw materials and lack of knowledge about facilities of loan for purchasing raw materials. Arya et al. (2021) also came up with some similar results and reported that beekeepers mostly sold their honey directly to the processor. March and April were the most important months from view of level of production and disposal of honey. Unconditional weather and climatic conditions, bee diseases and unfixed price of honey were major problems faced by the beekeepers.

\section{CONCLUSION}

There is a vast scope of adoption of recommended beekeeping practices in Kumaon hills of Uttarakhand. Adoption of these practices will help to increase both quality as well as the quantity of honey which will ultimately add to the farmers income. To accomplish this, various research institutions are required to be enabled to conduct studies toward Innovation and adoption of recommended beekeeping practices. Also, relevant studies should be conducted with respect to the appropriate innovative technological packages for farmer conditions to solve current apiary related problems. There is an increasing demand for honey all around the globe as well as in India. Uttarakhand being a home to a large number of floras can be a good source of nectar flow for the reared honeybees resulting in good average honey production and therefore, beekeeping can result in good supplementary income generation. The native tribal population of Uttarakhand generally practice the traditional methods of beekeeping which results in poor honey yields. These traditional practices should be upgraded according to the climatic suitability of the hills and farmers should be encouraged to adopt the new advance practices to increase honey production.

\section{REFERENCES}

1) Arya, S., Kumar, A., Kumar, K. and Kumar, D. (2021). Major constraints faced by the beekeepers in production and marketing of honey in the Nainital district of Uttarakhand. The pharma innovation journal, 10(8): 276-279 pp

2) Bansal, K. Singh, Y. Singh, P. (2013). Constraints of Apiculture in India: International Journal of life Sciences Research, Vol, 1(1), pp. 1-4

3) Fikadu, A. A., Tilaye, A. K. and Mebrat, A. M. (2017). Adoption and intensity of use of modern beehives in wag Himra and North Wollo zones, Amhara region, Ethiopia. Ethiopian Journal of Economics, 24(2): 64-94pp.

4) Khan, M.S., Karnatak , A.K. and Srivastava, P. (2007). Beekeeping in Uttarakhand, Indian Bee Journal 69(1/4): $88-93$ pp

5) Kumar, Y., Nain, M.S., Peshin, R. and Yungchan, J. (2020). Constraints perceived by the beekeepers of Jammu province, adoption of scientific beekeeping practices. Indian journal of extension education, 56(4): 69-75 pp.

6) Kumbhare, N, V., Jirli,B., Gautam, U,S. and Singh, A,K (2020). Diffusion and adoption of innovation in agriculture. Handbook of agricultural extension, 264-266.

7) Shenkute, A., Getachew, Y., Assefa, D., and Adgaba, N. (2012). Honey production systems (Apismellifera L.) in Kaffa, Sheka and Bench-Maji zones of Ethiopia. Journal of Agricultural Extension and Rural Development, 4(19): 528-54pp.

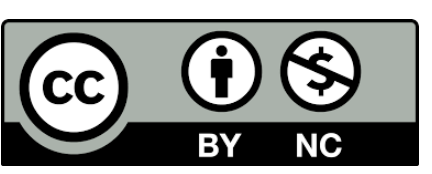

There is an Open Access article, distributed under the term of the Creative Commons Attribution - Non Commercial 4.0 International (CC BY-NC 4.0)

(https://creativecommons.org/licenses/by-nc/4.0/), which permits remixing, adapting and building upon the work for non-commercial use, provided the original work is properly cited. 